\title{
Sorvete de umbu e mangaba com propriedade funcional:
}

\section{processamento e caracterização}

\author{
Caroline dos Santos Meloㅁ, Igor Macedo Ferreira ${ }^{2}$, Ana Mara Oliveira e Silva ${ }^{3}$ e \\ Michelle Garcêz de Carvalho ${ }^{4}$
}

\begin{abstract}
Objetivou-se elaborar e avaliar formulações de sorvete com Bacillus clausii e frutooligossacarídeo. Inicialmente, foi realizada uma pesquisa com 66 consumidores de sorvete, por meio de questionários, para identificar quais frutas seriam adicionadas aos sorvetes. Em seguida, foram formulados 4 sorvetes (F1- sem fruta; F2 - com umbu; F3 com mangaba, e F4 - com umbu e mangaba), sendo esses, avaliados microbiologicamente (coliformes, Salmonella sp., Estafilococus coagulase positivo e fungos), sensorialmente (aceitação e preferência), físico-química e química (umidade, proteínas, lipídios, cinzas, vitamina $\mathrm{C}$, espécies reativas ao ácido tiobarbitúrico, 1,1-difenil-2-picrilhidrazil, fenólicos, sólidos solúveis, acidez e $\mathrm{pH}$ ), calorias e carboidratos. Para o sabor dos sorvetes, os consumidores escolheram a mangaba, seguido do umbu, e da mistura umbu e mangaba. Todas as formulações estavam seguras microbiologicamente, apresentaram alta aceitabilidade e garantiram a viabilidade do Bacillus clausii. Os sorvetes com frutas demonstraram ser fonte de compostos bioativos e apresentaram maior atividade antioxidante (vitamina C) do que o sorvete sem fruta (F1). A adição de frutooligossacarídeo e B. clausii não exerceu influência nas características avaliadas. Os sorvetes propostos são produtos inovadores e podem atender às expectativas do mercado consumidor por alimentos com alegação funcional e com frutas regionais.
\end{abstract}

Palavras-chave: Sorvete; Prebiótico; Bacillus clausii; Mangaba; Umbu.

\section{Functional property umbu and mangaba ice cream: processing and characterization}

The aim of the current study is to develop and evaluate ice cream formulations based on Bacillus clausii and on fructooligosaccharide. A survey based on questionnaires was initially conducted with 66 ice cream consumers in order to define the fruits to be added to the ice creams. Next, 4 ice creams (F1- without fruit; F2 - added with umbu; F3 - added with mangaba, and F4 - added with umbu and mangaba) were formulated and subjected to microbiological (coliforms, Salmonella sp., positive Staphylococcus coagulase and fungi), sensory (acceptance and preference), physicochemical and chemical (humidity, proteins, lipids, ash, vitamin $\mathrm{C}$, Thiobarbituric acid reactive substances, 1,1-diphenyl-2-picryl-hydrazil, phenols, soluble solids, acidity and $\mathrm{pH}$ ) evaluations, as well as to calorie and carbohydrate analysis. Mangaba was the main ice cream flavor selected by consumers; it was followed by umbu and umbu/mangaba mix. All formulations were microbiologically safe; they have shown high acceptability and

${ }^{1}$ Bacharel em Nutrição pela Universidade Federal de Sergipe. E-mail: carolinemenutri19@gmail.com. ID ORCID: https://orcid.org/0000-0003-1629-9855

2 Técnico do laboratório de Microbiologia de Alimentos, departamento de Nutrição da Universidade Federal de Sergipe. E-mail: engigormacedo@gmail.com. ID ORCID: https://orcid.org/0000-0002-0648-4937

${ }^{3}$ Professora do departamento de Nutrição da Universidade Federal de Sergipe. E-mail: anamaraufs@gmail.com. ID ORCID: https://orcid.org/0000-0003-0831-8833

${ }_{4}$ Professora do departamento de Nutrição da Universidade Federal de Sergipe. E-mail: michellegarcezpi@hotmail.com. ID ORCID: https://orcid.org/0000-0002-5714-9610. Endereço para

Correspondência: Av. Marechal Rondon, s/n - Jardim Rosa Elze, São Cristóvão - SE, 49100-000 
assured Bacillus clausii viability. Ice creams added with fruits were source of bioactive compounds and presented higher antioxidant activity (vitamin C) than the ice cream formulation without fruit (F1). Fructooligosaccharide and $B$. clausii addition to ice cream formulations did not influence the evaluated features. The herein suggested ice cream formulations are innovative products that can meet consumer market's expectations about food with functional claims and added with regional fruits.

Keywords: Ice cream; Prebiotics; Bacillus clausï; Mangaba; Umbu.

Submetido em: 15/06/2020

Aceito em: 12/02/2021

\section{INTRODUÇÃO}

Os sorvetes são gelados comestíveis e são obtidos a partir de uma emulsão de gorduras e proteínas, ou da mistura de água, açúcar e outros ingredientes que tenham sido submetidos ao congelamento, em condições tais que garantam a conservação do produto no estado congelado ou parcialmente congelado, durante o armazenamento, o transporte e a entrega ao consumo ${ }^{[1]}$.

O sorvete é um produto apreciado tanto por crianças como por adultos. Isso se deve às suas características sensoriais (matriz semissólida, congelada e aerada) e nutricionais, podendo fornecer proteínas, gorduras, energia, vitaminas $(\mathrm{A}, \mathrm{B} 1, \mathrm{~B} 2$, B6, C, D e K) e minerais (cálcio e fósforo) devido a adição de leite e derivados ${ }^{2]}$. Tendo em vista esse mercado e a busca pelos consumidores por alimentos saudáveis, é cada vez mais frequente a produção de gelados comestíveis com ingredientes funcionais, como probióticos, prebióticos e frutas como fontes de compostos bioativos ${ }^{[3]}$, os quais estão associados à promoção e/ou redução de fatores de risco para determinadas doenças ${ }^{[4]}$.

Os probióticos são microorganismos vivos que, quando administrados em quantias apropriadas, conferem benefícios à saúde ${ }^{[4]}$. Eles podem atuar melhorando a digestão da lactose em indivíduos intolerantes a lactose, atenuando a constipação, produzindo vitaminas, aumentando a absorção de minerais e vitaminas, reduzindo os níveis colesterol circulante, diminuindo a atividade de bactérias patogênicas como a Helicobacter pylori, estimulando o sistema imune e ajudando a reduzir o risco de câncer de colón ${ }^{[4,5]}$.
Já os prebióticos são carboidratos complexos, considerados fibras, resistentes às ações das enzimas salivares e intestinais, que ao atingirem o cólon, produzem efeitos benéficos à microbiota intestinal[ $[$. Dentre os prebióticos, destacam-se os frutooligossacarídeo (FOS) que são obtidos a partir da hidrólise da inulina, mas os FOS também estão presentes naturalmente em alguns vegetais e são produzidos industrialmente a partir de reação da enzima frutosil transferase sobre a sacarosel[].

Frutas como umbu (Spondias tuberosa Arruda Câmara) e a mangaba (Hancornia speciosa Gomes) são consumidas in natura ou processadas, podendo ser utilizadas na elaboração de sorvetes, geleias e iogurtes ${ }^{[8,9,10,11]}$. O umbu possui frutos globosos ou ovóides, providos de polpa suculenta e sem fibras, com sabor doce-acidulado e muito agradável[12]. Os frutos do umbuzeiro são fonte de vitaminas (A e C) e fósforo ${ }^{[11]}$.

A mangaba é naturalmente encontrada no Brasil, estando distribuída nas regiões, Sudeste, Norte, Centro-Oeste e Nordeste, mas é nos tabuleiros e nas baixadas litorâneas do Nordeste onde há abundância e está concentrada quase toda a produção brasileira ${ }^{[13]}$. É fonte de ferro $(2,8 \mathrm{mg} / 100 \mathrm{~g})$ e vitamina C $(33 \mathrm{mg} / 100 \mathrm{~g})^{[14]}$. A mangaba é uma fruta com importância social, econômica e cultural para as áreas em que ocorre. O estado de Sergipe é o maior produtor dessa fruta, a qual é encontrada em populações nativas e é explorada quase inteiramente de forma extrativista[15]. Além disso, o consumo de mangaba pode trazer benefícios a saúde, pois ela fornece antioxidantes naturais ${ }^{[16]}$. 
Direito Humano à Alimentação Adequada e a pandemia de Covid. Daufenback, Coelho \& Bógus.

Dessa forma, visando ampliar o consumo de umbu e mangaba, e disponibilizar para o consumidor um sorvete com alegação de propriedade funcional, objetivou-se elaborar e avaliar formulações de sorvete com ou sem polpa de umbu e mangaba, adicionados de frutooligossacarídeo e Bacillus clausii.

\section{MATERIAIS E MÉTODOS}

\section{Questões éticas}

Este trabalho foi previamente aprovado pelo Comitê de Ética em Pesquisa da Universidade Federal de Sergipe, em 12 de junho de 2015, número do parecer 1.106.440.

\section{Pesquisa com consumidores}

Antes da elaboração das formulações do sorvete de umbu com mangaba, foi realizada uma pesquisa prévia com 66 consumidores potenciais de sorvete. Os consumidores questionados (ambos os gêneros) estavam distribuídos entre alunos e servidores da Universidade Federal de Sergipe (UFS), no campus de São Cristóvão, com idade entre 18 e 45 anos. A pesquisa consistiu na aplicação de um questionário com 15 questões objetivas de múltipla escolha associadas ao: 1 - Sabor para o sorvete (umbu, mangaba, umbu e mangaba, cajá ou outras). Observação: outros sabores foram sugeridos pelos consumidores (pitanga, mirtilo, coco, acerola com melancia, tamarindo, cajá, caju, melancia com hortelã, castanha e limão); 2 e 3 - Consumo (sim ou não) e frequência de consumir sorvete (raramente, uma vez por semana, uma vez ao mês, duas vezes ao mês) 4 e 5 - Consumo (sim ou não) e frequência de consumir alimentos funcionais (raramente, diariamente, duas ou três vezes por semana, uma vez ao mês, duas vezes ao mês); 6 - Tipo de ingrediente com propriedade funcional mais consumido (fibras, probióticos, ômega 3, fibras e probióticos); 7 Conhecimento sobre o efeito da fonte funcional consumida (sim ou não); 8 e 9 - Consumo (sim ou não) e frequência de produtos com duas frutas (raramente, diariamente, uma vez por semana, duas ou três vezes por semana, uma vez ao mês, duas vezes ao mês); 10 - Opinião sobre o sabor do umbu (indiferente, bom, delicioso, ruim, não combina); 11 - Opinião sobre o sabor da mangaba (indiferente, bom, delicioso, ruim, não combina); 12 - Opinião sobre o sabor na combinação do umbu e mangaba (Combina - sim, não combina - não); 13 Consumiria sorvete sabor umbu e mangaba (sim ou não); 14 - Quanto pagaria em $100 \mathrm{~g}$ do sorvete de umbu e mangaba $(\mathrm{R} \$ 0,50$ a $1,00, \mathrm{R} \$ 1,00$ a $\mathrm{R} \$ 2,00$, $\mathrm{R} \$ 2,00$ a $\mathrm{R} \$ 3,00) ; 15$ - Atributo mais importante em um produto (sabor, preço, marca, benefício à saúde).

\section{Elaboração do sorvete}

Para a elaboração do sorvete foram utilizados os seguintes ingredientes: polpa de umbu pasteurizada, polpa de mangaba pasteurizada, ovo integral em pó, leite integral UHT, creme de leite, açúcar cristal, frutooligossacarídeo, probiótico, liga neutra, emulsificante e gordura hidrogenada. O probiótico era composto por esporos do Bacillus clausii adquiridos comercialmente em farmácia sob a forma de flaconetes (Enterogermina $\left.{ }^{\circledR}\right)$, contendo, segundo informações do fabricante, $10^{9}$ UFC de esporos do microrganismo por unidade de flaconete (5mL). A ativação do Bacillus clausii foi realizada em meio Brain Herat Infusion (BHI) na proporção 1:1 v/v, por $24 \mathrm{~h}$ a $37^{\circ} \mathrm{C}$ em banho-maria ${ }^{[17]}$. Após a ativação do B. clausii adicionaram-se $10 \mathrm{~mL}$ do mesmo em cada $50 \mathrm{~g}$ de sorvete ${ }^{[3]}$.

\section{Concentração das polpas de umbu e mangaba}

A concentração objetivou reduzir a umidade em até $50 \%$ para enfatizar as características sensoriais (sabor, cor, aroma), sendo essa etapa realizada individualmente para cada polpa. Para isso, usou-se polpa de umbu e mangaba da mesma marca e lote comercial. Antes da desidratação, cada embalagem das polpas foi higienizada (lavagem com água corrente $\rightarrow$ imersão em solução clorada a $200 \mathrm{ppm} / 10$ minutos $\rightarrow$ enxágue com água corrente), em seguida as embalagens foram abertas com auxílio de tesoura culinária de inox, e a polpa adicionada em panela de inox para cocção em fogão à $90^{\circ} \mathrm{C}$ durante 60 minutos, sob agitação constante. Após cocção, realizou-se o resfriamento $\left(5^{\circ} \mathrm{C}\right) \mathrm{em}$ banho de gelo com água, seguido do acondicionamento em sacos de polietileno e congelamento a $-18^{\circ} \mathrm{C}$ até o início do preparo do sorvete. 
Direito Humano à Alimentação Adequada e a pandemia de Covid. Daufenback, Coelho \& Bógus.

\section{Preparo das formulações do sorvete}

Foram desenvolvidas quatro formulações (F1, F2, F3 e F4) de sorvete. A diferença entre as formulações se refere à ausência de polpa de fruta, o tipo de polpa de fruta adicionada e adição de frutooligossacarídeo (FOS). Apenas a F1 não houve adição de fruta e FOS. Nas formulações 2, 3 e 4, substitui-se parte do açúcar por FOS. A adição de FOS aproximou-se de $5 \%$ por porção de sorvete pronto (60g). Quanto à adição de polpa de fruta, na F2 adicionou-se polpa de umbu, F3 adicionou-se polpa de mangaba, e na F4 adicionou-se polpas de umbu e mangaba. Inicialmente foram realizados prétestes, sem participação de provadores, com os ingredientes citados acima, com a finalidade de reproduzir um sorvete com características sensoriais aceitáveis. $\mathrm{Na}$ Tabela 1 estão dispostas as formulações e seus respectivos ingredientes.

Tabela 1. Formulações de sorvete sem e com frutas. São Cristóvão. 2020.

\begin{tabular}{ccccc}
\hline & \multicolumn{3}{c}{ Formulações } \\
\cline { 2 - 5 } Ingredientes & F1* & F2* & F3* & F4* \\
\hline Leite integral UHT & $37 \mathrm{~g}$ & $17 \mathrm{~g}$ & $17 \mathrm{~g}$ & $17 \mathrm{~g}$ \\
Creme de leite UHT & $34 \mathrm{~g}$ & $10 \mathrm{~g}$ & $10 \mathrm{~g}$ & $10 \mathrm{~g}$ \\
Ovo integral em pó & $2 \mathrm{~g}$ & $2 \mathrm{~g}$ & $2 \mathrm{~g}$ & $2 \mathrm{~g}$ \\
Açúcar cristal & $10 \mathrm{~g}$ & $1,6 \mathrm{~g}$ & $1,6 \mathrm{~g}$ & $1,6 \mathrm{~g}$ \\
FOS & - & $8,4 \mathrm{~g}$ & $8,4 \mathrm{~g}$ & $8,4 \mathrm{~g}$ \\
Gordura hidrogenada & $15 \mathrm{~g}$ & $15 \mathrm{~g}$ & $15 \mathrm{~g}$ & $15 \mathrm{~g}$ \\
Emulsificante & $1 \mathrm{~g}$ & $1 \mathrm{~g}$ & $1 \mathrm{~g}$ & $1 \mathrm{~g}$ \\
Liga neutra & $1 \mathrm{~g}$ & $1 \mathrm{~g}$ & $1 \mathrm{~g}$ & $1 \mathrm{~g}$ \\
Polpa de umbu & - & $40 \mathrm{~g}$ & - & $20 \mathrm{~g}$ \\
Polpa de mangaba & - & - & $40 \mathrm{~g}$ & $20 \mathrm{~g}$ \\
Probiótico & $20 \mathrm{~mL}$ & $20 \mathrm{~mL}$ & $20 \mathrm{~mL}$ & $20 \mathrm{~mL}$ \\
\hline
\end{tabular}

*F1 (Formulação 1); F2 (Formulação 2); F3 (Formulação 3); F4 (Formulação 4).

A elaboração dos sorvetes seguiu as seguintes etapas: pesagem dos ingredientes em balança semi-analítica $\rightarrow$ mistura dos ingredientes (exceto emulsificante, liga neutra e probiótico) em liquidificador (Wallita) (2 minutos/velocidade 3) $\rightarrow$ cocção em panela de inox sob agitação constante $\left(80^{\circ} \mathrm{C}^{\circ} / 5\right.$ minutos $) \rightarrow$ resfriamento em banho de gelo até $5^{\circ} \mathrm{C} \rightarrow$ filtração da calda em peneira de inox $\rightarrow$ acondicionamento em potes de polietileno com tampa sob refrigeração $\left(5^{\circ} \mathrm{C} / 8 \mathrm{~h}\right) \rightarrow$ transferência da calda para batedeira (Arno) $\rightarrow$ adição à calda do emulsificante, liga neutra e Bacillus clausii $\rightarrow$ mistura em batedeira (2 minutos/velocidade 2) $\rightarrow$ transferência para sorveteira (Fun Kitchen) para mistura $\left(5^{\circ} \mathrm{C} / 15\right.$ minutos $) \rightarrow$ acondicionamento em potes de polietileno com tampa (500g) $\rightarrow$ congelamento em freezer doméstico (GE SMART FRESH 410) $\left(-18^{\circ} \mathrm{C} / 5 \text { horas }\right)^{[3]}$. Os sorvetes permaneceram congelados até o início das análises por um período máximo de 72 horas.

\section{Análise microbiológica}

Antecedeno a análise sensorial, $200 \mathrm{~g}$ de cada formulação foram encaminhadas ao Laboratório de Microbiologia de Alimentos do Departamento de Nutrição da UFS, Campus São Cristóvão/SE, onde foram realizadas as seguintes análises microbiológicas: enumeração de bolores e leveduras (fungos), coliformes totais e termotolerantes, Estafilococus coagulase positivo e pesquisa de Salmonella sp. Os fungos e Estafilococus coagulase positivo são expressos em unidades formadoras de colônias (UFC) por grama de sorvete, os coliformes totais e termotolerantes são expressos em número mais provável (NMP)/g de sorvete, enquanto a pesquisa Salmonella sp. expressa em ausência ou presença em $25 \mathrm{~g}$ de sorvete ${ }^{[18]}$. Observou-se também a quantidade de colônias de Bacillus clausii nos sorvetes, sendo expresso em UFC Bacillus clausii/g de sorvete ${ }^{[3]}$. 


\section{Análise sensorial}

Atestada a segurança microbiológica dos sorvetes, procedeu-se com a avaliação sensorial das formulações de sorvete (F1, F2, F3 e F4), a qual foi realizada por oitenta provadores não treinados (18 a 50 anos) de ambos os sexos, em cabines individuais iluminadas com luz branca. Antes da degustação os provadores preencheram um formulário com suas informações pessoais e aspectos relacionados ao sorvete (alergia ou intolerância alimentar, gostar ou não, frequência de consumo, importância de alimentos funcionais). Posteriormente os provadores foram instruídos a ler e assinar o Termo de Consentimento Livre e Esclarecido (TCLE) antes de realizar a análise sensorial. Aproximadamente $20 \mathrm{~g}$ de cada amostra foram servidas a $0^{\circ} \mathrm{C}$ em copos de polietileno codificados com algarismos de três dígitos, as quais apresentadas de forma simultânea e casualizada, sendo avaliadas quanto à sua preferência (teste de ordenação), aceitação (escala hedônica) e intenção de compra.

A preferência das formulações foi analisada de acordo com as somas das ordens das formulações, as quais são comparadas com o valor absoluto crítico de diferença de soma de ordens (diferença mínima significativa) para estabelecer preferência significativa $(p<0,05)$, obtido em tabela específica. $\mathrm{Na}$ tabela de Friedman o valor absoluto crítico é 42 , tomando como referência que foram 4 amostras e 80 provadores. Se a diferença entre as somas (preferência de cada formulação) for maior ou igual a 42, há diferença significativa $(p<0,05)$ de preferência entre as formulações. A aceitação foi verificada pela escala hedônica estruturada de 9 pontos, no que refere a aparência, sabor, doçura, textura e impressão global. A escala de intenção de compra variou de um a cinco ${ }^{[19]}$. Foi avaliado o Índice de Aceitabilidade (IA), por meio da expressão IA (\%) $=\mathrm{A} \times 100 / \mathrm{B}$, em que, $\mathrm{A}=$ nota média obtida para $\mathrm{o}$ produto e $\mathrm{B}=$ nota máxima dada ao produto. O IA é considerado de boa aceitação quando $\geq 70 \%{ }^{[20]}$.

\section{Caracterização química e físico-química}

Foram adotados os seguintes parâmetros analíticos para a caracterização de todas as formulações de sorvete: umidade, proteína, lipídios, cinzas, $\mathrm{pH}$, sólidos solúveis totais (SST), $\mathrm{pH}$, vitamina $\mathrm{C}$ e acidez total titulável (AT'T). As análises foram realizadas em triplicata e de acordo com as normas analíticas do Instituto Adolf Lutz ${ }^{[1]}$. Também foi verificada a peroxidação lipídica no que se referem aos TBARS (espécies reativas ao ácido tiobarbitúrico) sendo expresso em $\mathrm{mg}$ de malonaldeído/100g de amostra ${ }^{[22]}$. Os carboidratos totais $(\mathrm{CHO})$ foram determinados através de cálculo por diferença: $\mathrm{CHO}=100-$ (umidade + cinzas + proteínas + lipídios totais) ${ }^{[23]}$. O valor calórico total foi estimado através dos seguintes fatores de conversão: $4 \mathrm{kcal} / \mathrm{g}$ para proteínas e carboidratos e $9 \mathrm{kcal} / \mathrm{g}$ para os lipídios ${ }^{[2]}$. Para a avaliação dos fenólicos totais e DPPH (2,2- difenil-1-picrilhidrazil), foram obtidos extratos a partir de $1 \mathrm{~g}$ da amostra de sorvete, o qual foi diluído em $10 \mathrm{~mL}$ de solução metanólica (80: 20 metanol/água), verificouse o conteúdo de fenólicos totais, expressos em ugEq de ácido gálico $/ 100 \mathrm{~g}$ de amostra ${ }^{[2]}$ e da capacidade antioxidante do sorvete pelo método do sequestro do DPPH (radical 2,2-diphenyl-1-picrylhydrazyl), sendo expresso em mg de EqTrolox/ 100g de amostra ${ }^{[25]}$.

\section{Análise estatística}

Para a análise estatística foi utilizado o software IBM SPSS versão 21 de 2012 (USA), sendo a estatística aplicada aos resultados obtidos na análise sensorial, química e físico-química. As médias que se apresentaram homogêneas $(p>0,05)$ foram submetidas ao teste de Tukey. Os valores- $p$ foram considerados significativos quando menores que 0,05 .

\section{RESULTADOS E DISCUSSÃO}

\section{Pesquisa com consumidor}

Em relação à escolha da fruta para dar sabor ao sorvete, a mangaba foi a mais indicada pelos consumidores (25), seguido do umbu (14), mistura da mangaba e umbu (12), cajá (5) e demais sabores (limão, castanha, mirtilo, melancia com hortelã, tamarindo, pitanga, caju, coco, mangaba com umbu e cajá, acerola com melancia) foi escolhido por 1 dos consumidores (15). Diante disso, verifica-se o potencial de consumo do sorvete elaborado com essas duas frutas, deixando claro que os sorvetes deveriam ser formulados com esses sabores, sendo 
assim, escolhidas para o projeto. A escolha da mangaba em maior percentual pode estar associada ao fato dessa fruta ser muito apreciada pela população sergipana e Sergipe ser o maior produtor dela no Brasil[15].

Dos consumidores questionados, a maioria afirmou que consumia sorvete (54), com maior frequência entre uma (18) a duas vezes por mês (21), além disso, a maioria (51) preocupa-se em consumir alimentos funcionais com maior frequência diária (27). Entre os tipos de fonte alimentícia com propriedade funcional (fibras, probióticos, ômega 3, fibras e probióticos) as fibras foram indicas em sua maioria (57), sendo que apenas 13 dos 66 entrevistados tinham conhecimento sobre os efeitos de alimentos com propriedades funcionais.

Quando questionados sobre o consumo de produtos mistos (com duas frutas), 48 consumidores, alegaram que já haviam consumido algum produto misto (sorvete, suco, picolés e iogurte), sendo que 14 dos entrevistados nunca haviam consumido, e raramente (22) foi o mais indicado pelos consumidores. Quanto ao sabor de mangaba ou umbu, a maior frequência de resposta ficou entre bom (27 a 30 consumidores) e delicioso (20 a 30 consumidores). A maioria dos consumidores (42) responderam que o sorvete ficaria bom com a junção de umbu e mangaba, assim como 14 indicaram que a mistura dessas frutas deixaria o sorvete delicioso, e 10 indicaram que a mistura de umbu com mangaba ficaria ruim ou seria indiferente.

Quanto ao sorvete com a mistura de umbu e mangaba, 57 consumidores; afirmaram que combinaria o sorvete com esse mix de frutas. Os entrevistados responderam em sua maioria (36) que pagariam entre 2,00 a 3,00 Reais em cada $100 \mathrm{~g}$ do sorvete de umbu e mangaba proposto no estudo. $\mathrm{O}$ sabor foi escolhido pela maioria (45) como o fator mais importante no momento da compra de um produto alimentício, seguido dos benefícios à saúde (17), marca (3) e preço (1). Em um estudo realizado com 55 provadores, a maioria dos entrevistados também citou o sabor como o principal fator decisivo na hora da compra de um produto[26].

\section{Análise microbiológica do sorvete}

A RDC no 12 do Ministério da Saúde ${ }^{[27]}$ regulamenta os padrões microbiológicos para alimentos e bebidas e estabelece, para sorvete, níveis de coliformes termotolerantes (até $50 \mathrm{NMP} / \mathrm{g}$ de sorvete), Estafilococus coagulase positivo (até 500UFC/ g de sorvete) e ausência de Salmonella sp em $25 \mathrm{~g}$ de sorvete. Dessa forma, após a análise microbiológica das quatro formulações de sorvete, observou-se que não houve crescimento de colônias de fungos ( $<1 \mathrm{X} 10^{2}$ (estimado) UFC/g de sorvete), de coliformes totais e termotolerantes $(<3 \mathrm{NMP} / \mathrm{g}$ de sorvete) e de colônias típicas de Estafilococus coagulase positivo ( $<1 \times 10^{2}$ (estimado) UFC/g de sorvete), e de Salmonella sp. Dessa forma, todas as formulações de sorvete elaboradas neste estudo estavam seguras do ponto de vista higiênico-sanitário para serem degustadas pelos provadores na análise sensorial, visto que o resultado foi inferior ao limite máximo estabelecido pela RDC no $12^{[27]}$.

O Bacillus clausii permaneceu viável nas quatro formulações de sorvete. Sendo assim, os sorvetes propostos mostraram ser um meio propício para os esporos do B. clausii. A contagem de B. clausii variou de 5,0 × $10^{8}$ UFC Bacillus clausii/g de sorvete (F2, F3 e F4) a 1,0 x $10^{9}$ UFC Bacillus clausii/g de sorvete (F1), estando dessa forma, de acordo com que é preconizado pela legislação, para que um alimento tenha propriedade probiótica, esse deve possuir uma quantidade mínima entre $10^{8}$ a $10^{9}$ $\mathrm{UFC} / \mathrm{g}^{[28]}$, sendo ainda necessário a comprovação analítica e clínica dessas propriedades funcionais ou de saúde para que seja possível alegar essa informação no rótulo do alimento[29].

\section{Análise sensorial do sorvete}

A aceitação sensorial e intenção de compra das quatro formulações de sorvete estão apresentadas na Tabela 2.

Observa-se que apenas a doçura e sabor não diferenciaram significativamente $(p>0,05)$ entre as formulações. As formulações 1, 3 e 4 foram as que mais se assemelharam na aceitabilidade (aparência, textura e impressão global), com destaque para a F2 que diferiu $(p<0,05)$ da F1 na textura, assim como, diferiu da F1 e F4 na impressão global. No que se refere à escala hedônica, as formulações de sorvete ficaram entre gostei ligeiramente (6) e gostei muito (8) (Tabela 2). 
Direito Humano à Alimentação Adequada e a pandemia de Covid. Daufenback, Coelho \& Bógus.

Tabela 2. Aceitação sensorial e intenção de compra de sorvetes. São Cristóvão, 2020.

\begin{tabular}{rrrrr}
\hline & \multicolumn{4}{c}{ Formulações } \\
Atributos sensoriais & F1* & F2* & F3* $^{*}$ & F4* $^{*}$ \\
\hline Aparência & $7,82 \pm 1,32^{\mathrm{a}}$ & $6,24 \pm 1,88^{\mathrm{b}}$ & $7,54 \pm 1,18^{\mathrm{a}}$ & $7,62 \pm 1,31^{\mathrm{a}}$ \\
Doçura & $7,18 \pm 1,89^{\mathrm{a}}$ & $6,39 \pm 2,45^{\mathrm{a}}$ & $7,15 \pm 1,60^{\mathrm{a}}$ & $7,09 \pm 1,89^{\mathrm{a}}$ \\
Sabor & $6,81 \pm 1,98^{\mathrm{a}}$ & $6,58 \pm 2,42^{\mathrm{a}}$ & $6,63 \pm 1,89^{\mathrm{a}}$ & $6,88 \pm 1,95^{\mathrm{a}}$ \\
Textura & $7,68 \pm 1,55^{\mathrm{a}}$ & $6,26 \pm 2,07 \mathrm{~b}$ & $6,65 \pm 1,93^{\mathrm{b}}$ & $7,01 \pm 1,95^{\mathrm{ab}}$ \\
Impressão global & $7,07 \pm 1,77^{\mathrm{a}}$ & $6,19 \pm 1,99^{\mathrm{b}}$ & $6,63 \pm 1,71^{\mathrm{ab}}$ & $6,97 \pm 1,74^{\mathrm{a}}$ \\
\hline Intenção de compra & $3,53 \pm 1,46^{\mathrm{a}}$ & $2,88 \pm 1,45^{\mathrm{b}}$ & $3,27 \pm 1,43^{\mathrm{ab}}$ & $3,42 \pm 1,36^{\mathrm{ab}}$ \\
\hline
\end{tabular}

*Médias e desvio padrão (DP). Letras diferentes na linha indicam diferença significativa pelo teste de Tukey ( $p<0,05)$. F1: sem fruta; F2: com umbu; F3: com mangaba; e F4: com umbu e mangaba.

Dos parâmetros avaliados, a aparência dos sorvetes (F1, F3 e F4) obteve a maior média de aceitação, o que pode estar relacionado à cor e ao aspecto visual principalmente observado pelo derretimento, sendo que o sorvete formulado com o umbu derretia mais rapidamente que os demais, o que pode ter influenciado na aceitabilidade menor dessa formulação no que se refere à aparência. Já a doçura apresentou notas satisfatórias (gostei ligeiramente a gostei muito), visto que ela não pode ser excessiva, podendo dar ao produto um caráter enjoativo e não podem ser amargos ou ácidos, pois provavelmente seriam rejeitados pelos consumidores ${ }^{[2]}$. Por sua vez, o sabor é o fator que diferencia os alimentos e ele pode ser influenciado por inúmeras razões como, por exemplo, sensações térmicas, dolorosas e táteis [30].

A textura de um sorvete deve ser cremosa, não elástica e ter uma consistência firme ${ }^{[2]}$. Além disso, as formulações 1,3 e 4 demonstraram a mesma intenção de compra, assim como a F2, F3 e F4, apresentando uma escala entre talvez comprasse, talvez não comprasse (3) à provavelmente compraria (4). A intenção de compra está intimamente relacionada à aceitabilidade do parâmetro sabor, uma vez que o consumidor dá preferência de compra a produtos que apresentem um sabor mais agradável[9].

Diante disso, observa-se que a adição de probióticos e FOS ao sorvete não interferiu a aceitação sensorial e intenção de compra, e sim a adição da polpa de fruta às formulações (Tabela 2). Assim, a aceitabilidade obtida pelos sorvetes propostos no que se referem às formulações 1, 3 e 4, apontam que essas formulações apresentam maior potencial para comercialização, pois o consumidor tem se tornado cada vez mais exigente e qualidade sensorial é um dos fatores que promovem a fidelidade dos clientes com o determinado produto[30].

No que se refere à preferência sensorial, não houve diferença $(p>0,05)$ entre os sorvetes avaliados pelos provadores.

O Índice de Aceitabilidade (IA) obtido pelos atributos sensoriais das formulações de sorvete foram, respectivamente, $81,22 \%$ (F1), 70,33\% (F2), $76,89 \%$ (F3) e 79,11\% (F4). Todas as formulações propostas apresentaram bom potencial de consumo, uma vez que, os resultados para os diferentes atributos foram acima de $70 \%{ }^{[20]}$.

\section{Caracterização química e físico-química}

A umidade se apresentou como maior componente dos sorvetes propostos, o que é justificado pelo uso de leite UHT e/ou polpa de frutas nas formulações (Tabela 1). O teor de umidade encontrado nos sorvetes propostos (Tabela 3) aproximou-se do encontrado em sorvete de chocolate $(55 \%)^{[31]}$. 
Direito Humano à Alimentação Adequada e a pandemia de Covid. Daufenback, Coelho \& Bógus.

A formulação 1 obteve os maiores valores de umidade, cinzas, proteína e $\mathrm{pH}$ (Tabela 3), sendo este último de grande relevância, uma vez que os sorvetes com adição de frutas estão fora do $\mathrm{pH}$ ótimo de crescimento bacteriano e fúngico $(5,0$ a $7,0)^{[32]}$. Já a formulação 3 apresentou os maiores valores de lipídeos e energia (Tabela 3), o que pode ser explicado devido à maior densidade energética da mangaba em relação ao umbu, visto que a mangaba possui 2,37g/100g de lipídeos, 10g/100g de carboidratos e $66 \mathrm{kcal} / 100 \mathrm{~g}[33]$ enquanto a polpa do umbu possui apenas $0,08 \mathrm{~g} / 100 \mathrm{~g}$ de lipídio e $5 \mathrm{~g} / 100 \mathrm{~g}$ de carboidratos ${ }^{[34]}$. As formulações 2 e 4 apresentaram as maiores quantidades de carboidrato, o que pode estar associada à composição centesimal dessas formulações, uma vez que apresentaram menos teores de umidade, cinzas, lipídios e proteínas (Tabela 3).

Tabela 3. Características químicas e físico-químicas dos sorvetes. São Cristóvão, 2020.

\begin{tabular}{|c|c|c|c|c|c|}
\hline \multirow{2}{*}{ Características } & \multicolumn{4}{|c|}{ Formulações } & \multirow{2}{*}{ Padrão \# } \\
\hline & F1* & F2* & F3* & F4* & \\
\hline Umidade & $54,68 \pm 0,10^{a}$ & $52,36 \pm 0,54 \mathrm{~b}$ & $51,27 \pm 0,48 \mathrm{bc}$ & $50,80 \pm 0,63 \mathrm{c}$ & -- \\
\hline Cinzas & $0,59 \pm 0,01^{a}$ & $0,44 \pm 0,00^{\mathrm{b}}$ & $0,44 \pm 0,00^{\mathrm{b}}$ & $0,43 \pm 0,00^{\mathrm{b}}$ & -- \\
\hline Lipídio & $15,59 \pm 0,42^{\mathrm{b}}$ & $7,43 \pm 0,38^{\mathrm{d}}$ & $18,26 \pm 0,49^{a}$ & $9,50 \pm 0,16^{c}$ & 3 \\
\hline Proteína & $5,80 \pm 0,66^{a}$ & $3,34 \pm 0,19 \mathrm{~b}$ & $3,71 \pm 0,33^{b}$ & $3,75 \pm 0,14^{b}$ & 2,5 \\
\hline Carboidrato & $23,34 \pm 0,0,37 \mathrm{c}$ & $36,43 \pm 0,67 \mathrm{a}$ & $26,32 \pm 0,65^{\mathrm{b}}$ & $35,51 \pm 0,66^{a}$ & -- \\
\hline Energia & $256,90 \pm 2,12^{\mathrm{b}}$ & $225,98 \pm 1,57 \mathrm{~d}$ & $284,51 \pm 1,62^{a}$ & $242,58 \pm 2,67 c$ & -- \\
\hline $\mathrm{pH}$ & $6,60 \pm 0,03^{a}$ & $2,68 \pm 0,36^{\mathrm{d}}$ & $3,88 \pm 0,01^{\mathrm{b}}$ & $3,37 \pm 0,01^{\mathrm{c}}$ & -- \\
\hline ATT & $1,76 \pm 0,14^{\mathrm{d}}$ & $13,66 \pm 0,53^{a}$ & $9,26 \pm 0,07 \mathrm{c}$ & $10,77 \pm 0,23^{b}$ & -- \\
\hline SST & $30,64 \pm 0,72^{a}$ & $31,60 \pm 0,62^{a}$ & $31,50 \pm 0,36 \mathrm{a}$ & $31,80 \pm 0,43^{a}$ & -- \\
\hline Vit. C & $2,10 \pm 0,10^{\mathrm{d}}$ & $3,18 \pm 0,12^{c}$ & $6,06 \pm 0,11^{a}$ & $5,31 \pm 0,11^{\mathrm{b}}$ & -- \\
\hline DPPH & $0,63 \pm 0,05^{c}$ & $64,16 \pm 0,42^{\mathrm{b}}$ & $66,75 \pm 5,42^{\mathrm{b}}$ & $79,37 \pm 3,87 \mathrm{a}$ & -- \\
\hline Fenólicos totais & $\mathrm{Nd}$ & $0,08 \pm 0,01^{b}$ & $0,17 \pm 0,01^{\mathrm{a}}$ & $0,16 \pm 0,04^{a}$ & -- \\
\hline TBARS & $5,02 \pm 0,25^{c}$ & $6,83 \pm 0,16^{\mathrm{b}}$ & $13,13 \pm 0,29 a$ & $4,47 \pm 0,37 \mathrm{c}$ & -- \\
\hline
\end{tabular}

*Médias e desvio padrão (DP). Umidade e cinzas expressos em \%. Lipídios, proteína e carboidratos expressos em g/100g. Energia expresso em kcal/100g. Acidez total: expressos em g de ácido cítrico $/ 100 \mathrm{~g}$ de amostra; Sólidos solúveis totais: expressos em ${ }^{\circ}$ Brix. Fenólicos totais (FT): expresso em mmol de equivalentes de ácido gálico/100g amostra; DPPH (1,1-difenil-2-picril-hidrazil): expresso em micro mol equivalente de trolox/100 g de amostra; FRAP (Redução do ferro): expresso em Kg equivalente de sulfato ferroso/100 g de amostra. Nd: não detectado. Letras diferentes na linha indicam diferença significativa pelo teste de Tukey ( $p<0$,05). (F1: sem fruta e sem FOS; F2: com umbu e FOS; F3: com mangaba e FOS; e F4: com umbu, mangaba e FOS). \#Padrões legais ${ }_{[1]}$.

Os sólidos solúveis totais foram o único parâmetro que não variou nas formulações (Tabela 3). Um valor similar $(29,75)$ foi encontrado[9] ao analisar uma amostra de sorvete de mangaba, justificando que os SST estavam associados à elevada quantidade de açúcares presentes em sua polpa in natura. Quanto maior a quantidade de sólidos solúveis, melhor será a cremosidade, textura e o derretimento do sorvete[35].

A acidez foi maior na formulação 2 , seguido das formulações 3 e 4 . O resultado deixa explícito que a presença de frutas na formulação eleva a acidez (Tabela 3). A acidez encontrada nos sorvetes está 
abaixo do que é normalmente encontrado em sorvetes industrializados (20) [36].

As formulações com presença de fruta apresentaram os maiores teores de Vitamina C, DPPH e fenólicos totais. Destaca-se a formulação 4 por apresentar os maiores níveis de DPPH e fenólicos totais, sendo possível relacionar a presença desse parâmetro à incorporação de frutas (Tabela 3). A atividade antioxidante pode ser justificada pela presença das frutas, visto que, foi descrito que os antioxidantes dietéticos, presentes principalmente nas frutas, ajudam a atenuar os efeitos prejudiciais de espécies oxidantes sobre a saúde humana[37].

O umbu, uma das frutas presentes na composição dos sorvetes, apresenta ação antioxidante, sendo provavelmente decorrente da presença dos compostos fenólicos. A atividade antioxidante é decorrente de substâncias que, mesmo presentes em baixas concentrações, comparadas ao que pode ser oxidado, tem o poder de inibir ou retardar significativamente a atividade oxidante ${ }^{[38]}$. Dessa forma, a adição da mangaba e umbu aos sorvetes agregou compostos bioativos (fenólicos) com atividade antioxidante.

Os menores valores de TBARS foram encontrados nas formulações 1 e 4, contudo, a peroxidação lipídica foi maior na formulação com polpa de mangaba (Tabela 3). Dessa forma, é possível associar a presença do umbu com a redução da peroxidação lipídica, pois foram encontrados uma menor quantidade dos produtos resultantes dessa reação. A presença de frutas não foi o único fator correlacionado a oxidação lipídica, visto que, na formulação sem frutas foi encontrado um valor baixo (Tabela 3). Os valores de TBARS refletem o teor de um dos produtos (malonaldeído) da oxidação dos lipídios ${ }^{[39]}$.

A adição de FOS e Bacillus clausii não interferiu nas características avaliadas (Tabelas 2 e 3), enquanto que a ausência e presença de frutas (umbu, mangaba e combinação dessas frutas) exerceram efeito significativo sobre os parâmetros avaliados. As características observadas nos sorvetes fazem deles produtos com potencial para comercialização. Considerando que a aceitabilidade sensorial (impressão global), a intenção de compra e a preferência das formulações 1,3 e 4 , foram as mesmas, podemos supor que nutricionalmente a mais indicada é a formulação 1, por possuir maior teor de proteínas, minerais, assim como, é mais viável comercialmente, pois a adição de polpas de frutas em substituição aos produtos lácteos (leite e creme de leite) irá aumentar $(20 \%$ a $50 \%)$ o preço final do produto. Embora as formulações com frutas sejam economicamente mais caras, não deixariam de ser uma nova opção pelo consumidor de sorvete e proporcionariam a valorização de frutas regionais.

\section{CONCLUSÃO}

A pesquisa com consumidores de sorvete evidenciou que a mangaba seria a fruta mais propícia para adição aos sorvetes, seguido do umbu e combinação do umbu e mangaba. Observou-se que o sabor foi o principal fator determinante na escolha de um produto.

As formulações de sorvete propostas estavam microbiologicamente seguras e apresentaram a mesma aceitação (doçura e sabor) e preferência sensorial, além disso, índice de aceitação acima do mínimo para ser caracterizado como um sorvete com bom potencial para comercialização. Os sorvetes propostos mostraram ser um meio propício para os esporos do Bacillus clausii.

Quanto às características químicas e físicoquímicas dos sorvetes, os sólidos solúveis totais foram o único parâmetro que não deferiu significativamente entre as formulações, demonstrando que a adição e tipo de fruta exerceram influência nessas características. Sendo assim, os sorvetes com frutas (umbu, mangaba, umbu e mangaba) demonstraram ser fonte de compostos fenólicos, possuir maior atividade antioxidante (vitamina C), se comparados aos sorvetes sem fruta. Todas as formulações de sorvetes atenderam aos padrões (proteína e lipídeo) preconizados pela legislação.

A presença de frutooligossacarídeo, Bacillus clausii e frutas nos sorvetes pode ter agregado valor comercial, dando aos sorvetes propriedades funcionais. Sendo assim, os sorvetes propostos possuem características que os diferenciam dos sorvetes já existentes no mercado, sendo uma nova opção para o consumidor de sorvete com propriedades funcionais e frutas regionais. 
Direito Humano à Alimentação Adequada e a pandemia de Covid. Daufenback, Coelho \& Bógus.

\section{REFERÊNCIAS}

[1] Brasil. Agência Nacional de Vigilância Sanitária. Resolução no 266, de 22 de setembro de 2005. Estabelece o regulamento técnico para gelados comestíveis e preparados para gelados comestíveis. Diário Oficial. 2005 set.

[2] Estumano JFP, Melo KCN. Cartilha de boas práticas de fabricação na indústria de gelados comestíveis. Belém: SEBRAE; 2011.

[3] Conceição HBS, Melo CS, Ferreira IM, Silva AMO, Carvalho MG. Sorvete de umbu e mangaba: vida de prateleira e viabilidade do Bacillus clausii. Revista Brasileira de Higiene e Sanidade Animal. 2020; 14(1): 53-66.

[4] Souza JCB, Costa MDR, Rensis CMVB, Sivieri K. Ice cream: composition, processing and addition of probiotic. Alimentos e Nutrição. 2010; 21 (1): 155-165.

[5] Saad SMI. Probióticos e prebióticos: o estado da arte. Revista Brasileira de Ciências Farmacêuticas. 2006; 42(1): $1-16$.

[6] Minocha A. Probiotics for preventive health. Nutrition in Clinical Practice. 2009; 24(2): 227-241.

[7] Anjo DFC. Alimentos funcionais em angiologia e cirurgia vascular. Jornal Vascular Brasileiro. 2004; 3(2): $145-154$.

[8] Raizel R, Santini E, Kopper AM, Filho ADR. Efeitos do consumo de probióticos, prebióticos e simbióticos para o organismo humano. Ciências Saúde. 2011; 4(2): 66-74.

[9] Morzelle MC, Lamounier ML, Souza EC, Salgado JM, Vilas-Boas EVB. Caracterização físico-química e sensorial de sorvetes à base de frutos do cerrado. Revista do Instituto de Laticínios Cândido Tostes. 2012; 67(387):70-78.

[10] Souza HRS, Carvalho MG, Santos AM, Ferreira IM, Oliveira AM. Compostos bioativos e estabilidade de geleia mista de umbu (Spondias tuberosa arr. c.) e mangaba (Hancornia speciosa g.). Revista Brasileira de Higiene e Sanidade Animal. 2018; 12(2): 236-248.

[11] Marinho MVM, Figueirêdo RMF, Queiroz AJM, Santiago VMS, Gomes JP. Análise físico-química e sensorial de iogurte de leite de cabra com polpa de umbu. Revista Brasileira de Produtos Agroindustriais. 2012; 14(Especial): 497-510.

[12] Gondim PJS, Silva SM, Pereira WE, Dantas AL, Neto JRC, Santos LF. Qualidade de frutos de acessos de umbu-cajazeira (Spondias sp.). Revista Brasileira de Engenharia Agricola e Ambiental-Agriambi. 2013; 17(11): 1217-1221.

[13] Souza CS, Silva SA, Costa MAPC, Dantas ACVL, Fonseca AA, Costa CALC, Almeida WAB, Peixoto CP. Mangaba: perspectivas e potencialidades. Bahia Agrícola. 2005; 7(1): 29-31.

[14] Lima ILP, Scariot A. Boas práticas de manejo para o extrativismo sustentável da Mangaba. Brasília: Embrapa; 2010.

[15] Soares ANR, Vitória MF, Nascimento ALS, Ledo ADS, Rabbani ARC, Muniz ADS. Genetic diversity in natural populations of mangaba in Sergipe, the largest producer State in Brazil. Embrapa Tabuleiros CosteirosArtigo em periódico indexado (ALICE). 2016; 15(3): 0212.

[16] Almeida MMB, Sousa PHM, Arriaga ÂMC, Prado GM, Magalhães CE, Maia GA, Lemos TLG. Bioactive compounds and antioxidant activity of fresh exotic fruits from northeastern Brazil. Food Research International. 2011; 44(7): 2155-2159.

[17] Souza ALC. Desenvolvimento de novos produtos probióticos a partir do caju (Anacardium occidentale L.) [tese]. São Cristóvão: Universidade Federal de Sergipe; 2017.

[18] Silva N, Junqueira VCA, Silveira NFA, Taniwaki MH, Gomes RAR, Okazaki MM. Manual de métodos de análise microbiológica de alimentos e água. 5. ed. São Paulo: Blucher; 2017.

[19] Minim VPR. Análise Sensorial: estudos com consumidores. 3. ed. Viçosa: Editora UFV; 2013.

[20] Dutcosky SD. Análise Sensorial de Alimentos. 3. ed. Curitiba: Champagnat; 2011.

[21] Instituto Adolfo Lutz. Métodos físico-químicos para análise de alimentos. 4. ed. São Paulo: Instituto Adolfo Lutz; 2008.

[22] Ohkawa H, Ohishi N, Yagi K. Assay for lipid peroxides in animal tissues by thiobarbituric acid reaction. Analytical biochemistry. 1979; 95(2): 351-358.

[23] Brasil. Agência Nacional de Vigilância Sanitária. Resolução no 360, de 23 de dezembro de 2003. Aprova o regulamento técnico sobre rotulagem nutricional de alimentos embalados. Diário Oficial. 2003 dez.

[24] Swain T, Hillis WE. The phenolic constituents of Prunus domestica. I. - The quantitative analysis of 
Direito Humano à Alimentação Adequada e a pandemia de Covid. Daufenback, Coelho \& Bógus.

phenolic constituents. Journal of the Science of Food and Agriculture. 1959; 10(1): 63-68.

[25] Brand-Williams W, Cuvelier ME, Berset CLWT. Use of a free radical method to evaluate antioxidant activity. LWT - Food Science and Technology. 1995; 28(1): 25-30.

[26] Kassada AT, Campos BE, Branco GCS, Fioroto PO, Madrona GS. Sorbet a base de caldo de cana saborizado artificialmente. Revista GEINTEC - Gestão, Inovação e Tecnologias. 2015; 5(1): 1716-1725.

[27] Brasil. Agência Nacional de Vigilância Sanitária. Resolução no 12, de 02 de janeiro de 2001. Aprova o regulamento técnico sobre padrões microbiológicos para alimentos. Diário Oficial. 2001 jan.

[28] Brasil. Agência Nacional de Vigilância Sanitária. Resolução no 19 , de 30 de abril de 1999. Regulamento técnico de procedimentos para registro de alimento com alegação de propriedades funcionais e ou de saúde em sua rotulagem. Diário Oficial. 1999 mai.

[29] Brasil. Agência Nacional de Vigilância Sanitária. Resolução no 241, de 26 de julho de 2018. Regulamento técnico sobre os requisitos para comprovação da segurança e dos benefícios à saúde dos probióticos para uso em alimentos. Diário Oficial. 2018 jul.

[30] Teixeira LV. Análise sensorial na indústria de alimentos. Revista do Instituto de Laticínios Cândido Tostes. 2009; 64(366): 12-21.

[31] Rodrigues AP, Fontana CV, Padilha E, Silvestrin M, Augusto MMM. Elaboração de sorvete sabor chocolate com teor de gordura reduzido utilizando soro de leite em pó. Repositório Institucional da Universidade Federal do Rio Grande. 2006; 16(1): 55-62.
[32] Garcia-Cruz CH, Foggetti U, Silva AND. Alginato bacteriano: aspectos tecnológicos, características e produção. Química Nova. 2008; 31(7): 1800-1805.

[33] Silva MR, Lacerda DBCL, Santos GG, Martins DMO. Caracterização química de frutos nativos do cerrado. Ciência Rural. 2008; 38(6): 1790-1793.

[34] Carvalho AV, Nogueira JG, Mattietto RA. Elaboração e caracterização de estruturados de umbu. 21. ed. Brasília: Embrapa; 2015.

[35] Lamounier ML, Andrade FC, Mendonça CD, Magalhães ML. Desenvolvimento e caracterização de diferentes formulações de sorvetes enriquecidos com farinha da casca da jabuticaba (Myrciaria cauliflora). Revista do Instituto de Laticínios Cândido Tostes. 2015; 70(2): 93-104.

[36] Pazianotti L, Bosso AA, Cardoso S, Costa MR, Sivieri K. Características microbiológicas e físico-químicas de sorvetes artesanais e industriais comercializados na região de Arapongas - PR. Revista do Instituto de Laticínios Cândido Tostes. 2010; 65(377):15-20.

[37] Olivares LD, Cabrera GB, Martínez MTS. Importancia de los antioxidantes dietarios en la disminución del estrés oxidativo. Investigación y Ciencia. 2010; 18(50): 10-15.

[38] Guedes JRO. Efeitos sobre a saúde do consumo moderado de vinho tinto [tese]. Universidade Fernando Pessoa: Porto (Portugal); 2013.

[39] Gomes HA, Silva EN, Nascimento MRL, Fukuma HT. Evaluation of the 2-thiobarbituric acid method for the measurement of lipid oxidation in mechanically deboned gamma irradiated chicken meat. Food Chemistry. 2003; 80(3): 433-437. 